Article

\title{
Sustainable Cities and the Contribution of Historical Urban Green Spaces: A Case Study of Historical Persian Gardens
}

\author{
Raheleh Rostami ${ }^{1, *}$, Hasanuddin Lamit ${ }^{1, *}$, Seyed Meysam Khoshnava ${ }^{2}$, Rasoul Rostami ${ }^{3}$ \\ and Muhamad Solehin Fitry Rosley ${ }^{1}$
}

1 Faculty of Built Environment, Universiti Teknologi of Malaysia, Johor Bahru 81310, Malaysia; E-Mail: msfitry2@live.utm.my

2 Faculty of Civil Engineering, Universiti Teknologi of Malaysia, Johor Bahru 81310, Malaysia; E-Mail: mkseyed4@live.utm.my

3 Department of Architecture, Islamic Azad University Noor branch, Noor 4768-75353, Iran; E-Mail: rasoulrostami82@yahoo.com

* Authors to whom correspondence should be addressed; E-Mails: rraheleh2@live.utm.my (R.R.); b-hasanuddin@utm.my (H.L.); Tel.: 06-1-771-87197 (R.R.).

Academic Editor: Marc A. Rosen

Received: 21 July 2015 / Accepted: 3 September 2015 / Published: 29 September 2015

\begin{abstract}
Growing populations and rapid worldwide urbanization are recognized as constituting one of the most complex processes in the world and have raised concerns about the sustainability of cities. Sustainable development, a widely accepted strategic framework in city planning, singles out urban green spaces as a primary solution for addressing these issues. Growing empirical evidences indicate that the presence of natural areas contributes to a better quality of life in many ways. Urban green spaces serve as places of identity, memory, and belonging; enrich human life with meaning and emotions by providing important social and psychological benefits; and enhance the quality of life of citizens, which is a key component of sustainability. Despite our understanding of the benefits of urban green spaces, little is known about the benefits of historical urban green spaces. To highlight their importance with regard to environmental sustainability and citizens' well-being, this study analyzes a number of historical Persian gardens that are still actively used by urban residents. The findings suggest that historical Persian gardens could accommodate many social functions and address many of the psychological issues relating to urban dwelling. It has been generally acknowledged that sense of community and place attachment is pivotal to creating sustainable urban environments. Historical gardens as physical components can
\end{abstract}


cohesively weave together many parts of cities of any cities while providing places for public congregation as well as attracting a variety of local economic activities. All these attributes can make historical Persian gardens as a valuable municipal resource and a key ingredient for city's living sustainability.

Keywords: sustainable development; urban green spaces; heritage; identity and belonging; well-being; quality of life

\section{Introduction}

Today, approximately half of the earth's human population lives in cities, and this phenomenon is progressively on the increase (United Nations, 2005) [1]. Overcrowding and the resulting unplanned growth are recognized as constituting one of the most complex processes in the world, raising concerns about the sustainability of cities and inquiries about how to achieve sustainable cities. This study aims to identify potential benefits of historical urban green spaces in relation to concept of urban sustainability. Accordingly, concept of sustainability, sustainable development, heritage, urban green spaces and quality of life and well-being are considered as the main outline of the study and discussed in the following sections.

\subsection{Sustainability and Sustainable Development}

The concept of sustainability has been an integral part of development work since the late 1980s. However, this word is often combined with concepts such as protection, support and continuity, its definition is not simple. Similarly, in the context of sustainable cities, there is no single accepted definition. Accordingly, concept of sustainable development that includes aspects of urban planning and community development is usually considered. The concept of was framed in 1972 at the United Nations (UN) conference on the Human Environment in Stockholm (CHE, 1972) [2]. The concept has become well known since the Brundtland Commission released Our Common Future and its report on the state of the environment, development, and poverty in 1987. The report defines sustainable development as "development that seeks to meet the needs of the present without compromising the ability of future generations to meet their own needs" (World Commission on Environment and Development, 1987) [3]. This definition indicates that sustainable development is a future-oriented process, which is also rooted in old customs and the traditional cultures of mankind. In this regard, heritage and its effects on quality of life and social well-being (Tweed and Sutherland, 2007) [4], is seen as major components of the social and cultural dimensions of sustainability (Vileniske, 2008) [5]. Heritage is open to constant revision and change and are also both sources and results of social conflict (Graham and Howard, 2008) [6]. They are often used as a form of collective memory, a social construct shaped by the political, economic and social concerns of the present (Halbwachs and Coser, 1992) [7] and the study of heritage does not involve a direct engagement with the study of the past (Graham and Howard, 2008) [6]. Instead, the contents, interpretations and representations of the heritage resource are selected according to the demands of the present and, in turn, bequeathed to an imagined future (Ashworth et al., 2007) [8]. That is, heritage is 
present-centered and is created, shaped and managed by, and in response to, the demands of the present (Graham and Howard, 2008) [6].

\subsection{Sustainability and Heritage}

According to UNESCO (2012) [9], heritage is not simply something handed down from the past, it is a process that must be actively constructed and maintained in the present if it is to have any sustainable future. The general social and cultural benefits of heritage have been noted by scholars. In this case, historic environments are widely acknowledged. Increasingly, heritage has been seen as a major component of social well-being and quality of life (Tweed and Sutherland, 2007) [4]. Cultural heritage is deemed as a precious and irreplaceable resource, essential to personal identity and improving the quality of life (Lowenthal, 2006) [10]. Heritage can boost the local and national economy and create jobs by attracting tourists and investment, and providing leisure, recreation, and educational facilities (Tweed and Sutherland, 2007 [4]; Nijkamp and Riganti, 2008 [11]; English Heritage Guidance Note to Circular, 2009 [12]). Cultural heritage is a "critical infrastructure" of modern cities, which provides "long-lasting and sustainable anchor points that may create stability in a permanently fluctuating and competitive environment" (Lazrak et al. 2009) [13]. Accordingly, cultural heritage is identified as an intermingling of past and present practices and also represents a bridge between the different periods, cultures, localities and the natural and the built environment or between nature and humans (Bajec, 2007) [14]. Therefore, the idea of sustainability had been extended to the arena of cultural development. In addition, cultural sustainability defined as the continuation of local values, way of life and identity (Heikkinen et al., 2007) [15]. Indeed, the notion of cultural sustainability, aimed at highlighting the significance of culture and its factors in local, regional and global sustainable development. The report of the World Commission on Culture and Development (WCCD, 1996) [16] also promoted the long-term needs of future generations for access to cultural resources (Throsby, 2003) [17]. Indeed, Current attempts to establish sustainability indicators focus on creating specific, practical indicators for individual people that are embedded within a common framework (Huayhuaca et al., 2010 [18]; Valentin and Spangenberg, 2000 [19]).

This idea changes the traditional vision of sustainable development (SD) considered by researchers from the perspective of its economic, environmental/ecological, and social-cultural dimensions, and sustainability as a measure of the associated impacts within each of these dimensions (Spangenberg and Valentin, 1999 [20]; Eden et al., 2000 [21]; Valentin and Spangenberg, 2000 [19]). That is, the implementation of Agenda 21, and an increasingly sophisticated understanding of sustainable development, has resulted in the addition of a fourth institutional dimension and also to the creation of a prism of sustainability framework (PoS) (Figure 1; Spangenberg and Valentin, 1999 [20]; Eden et al., 2000 [21]; Spangenberg, 2002 [22]), as a more holistic model of sustainable development. In this framework, the institutional dimension refers to the level of public participation in political governance (Gunn and Var 2002 [23]; Speck 2002 [24]; Waldron and Williams 2002 [25]), and includes norms, values and practices applied to certain contexts via management interventions (Johnson and Wilson, 2000 [26]; van der Duim and Caalders, 2002 [27]; Mowforth and Munt, 2003 [28]) as well as crucial interpersonal processes, such as communication, public involvement, rules and government systems (Spangenberg, 2002) [22]. Hence, relying on established frameworks such as the prism of sustainability which designed to emulate the Brundtland Report's definition of sustainable development (Spangenberg 
and Valentin, 1999) [20] could be expedient to operationalize and evaluate complex concepts such as sustainable city. Indeed, interactions between social sustainability and urban form, depends sustainability upon on tangible and measurable aspects of community and neighborhood life, such as: interactions in the community/social networks; community participation; Pride/sense of place; community stability; and security (crime) (Bramley et al., 2006) [29]. Among them, sense of place, belonging and unity are frequently considered essential to the recognition and formation of heritage (Graham and Howard, 2008) [6]. Sense of place considered as an umbrella concept that containing other concepts like place attachment, identity and awareness (Shamai, 1991) [30]. According to Tate (Tate, 2005) [31], local identity refers to a sense of place or genius loci (pervading spirit of place). It taps the broad realms of environmental meaning, and represents a complex concept of human-environment relationships (Kaltenborn, 1998) [32]. Sense of place is a multidimensional concept represents emotions, beliefs, and behavioral commitments specific to particular geographic settings (Cottrell and Cottrell, 2015) [33]. It is created through the interaction of people and places, and experience of place cannot be separated from the specific situation and the behaviors occurring in that place (Semken, 2005) [34]. In addition, a positive sense of place creates a sense of attachment and it is considered as a social sustainability indicator (Nash and Christie, 2003) [35]. A sense of attachment to a place can enhance the emotional bond to that place (Rogan, 2005) [36] and evoke a sense of belonging to towns and society, which consequently enhances society's general wellbeing. Such sense of place can be affected by the perceived quality of that place (Talen, 1999) [37] and manifest itself as a common norm and code of behavior (Kearns and Forrest, 2000) [38]. Hence, sense of place is considered in this research as one possible approach to better understand setting qualities important to visitors and the connection to the psycho-social context of experience (Bott, 2000 [39]; Williams and Hall, 2002 [40]; Pretty et al., 2003 [41]; Gross and Brown, 2008 [42]; Lew, 2014 [43]).

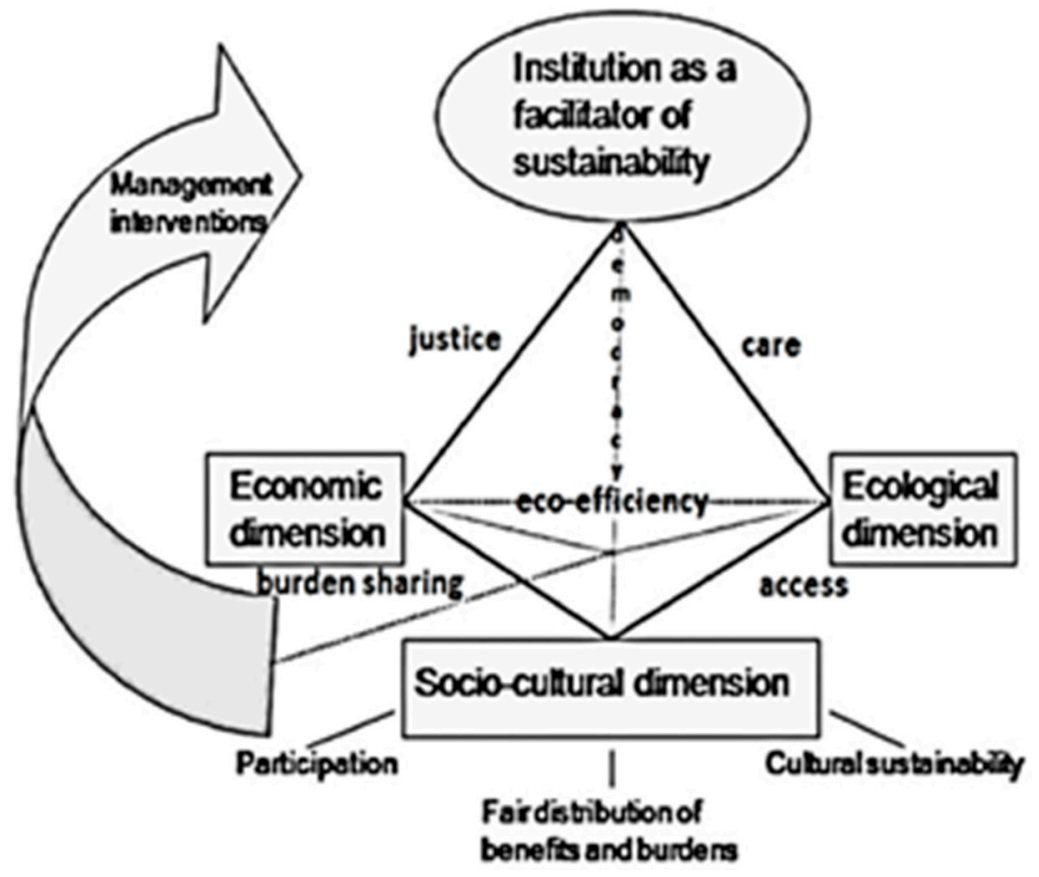

Figure 1. Modified prism of sustainability with sociocultural emphasis (adapted from Puhakka et al., 2013 [44]; Cottrell and Raadik, 2008 [45]; Cottrell et al., 2007 [46]; Valentin and Spangenberg, 2000 [19]). 


\subsection{Sustainability, Quality of Life and Well-Being}

The term "well-being" has been defined in various ways using socio-economic, psychological, and psychosocial parameters as well as feelings of connectedness to nature (Bell, 2005 [47]; Dutcher et al., 2007 [48]). The World Health Organization (WHO, 1948) [49] (p. 100) defines health and well-being as " a state of complete physical, mental and social well-being and not merely the absence of disease or infirmity". Greenberg (Greenberg, 1985) [50] (p. 404) suggests that wellness (or well-being) differs from health in that it "is the integration of physical, emotional, mental, spiritual and social health at any level of health or illness". That is, the term "well-being" includes material security, personal freedoms, good social relations and physical health, whereas the term "health" includes biological, sociological, economic, environmental, cultural, and political factors (Millennium Assessment, 2003) [51]. Based on this definition, a person might be regarded as achieving the status of well-being within one of the domains of health, which is defined as asymmetrical health (Greenberg, 1985) [50]. Well-being is defined in this study as an inner state of wellness that includes physical, social, mental, spiritual, and emotional states of consonance, which exist in healthy environments (Burns, 2006) [52] or are achieved through contact or engagement with natural environments and green spaces.

\subsection{Sustainability and Urban Green Spaces}

Based on principles that were presented in The European Landscape Convention (2000) [53], to achieve sustainability, development should be "based on a balanced and harmonious relationship between social needs, economic activities and the environment". Although consensus on the definition of sustainability had not yet been reached (Valentin and Spangenberg, 2000) [19], but sustainability is no longer considered solely an environmental concern; it incorporates economic and social dimensions (Cottrell et al., 2007 [46]; Cottrell and Raadik, 2008 [45]; Dempsey et al., 2009 [54]; Puhakka et al., 2009 [55]; Shen et al., 2009 [56]; Cottrell et al., 2013 [57]). In addition to environmental criteria (water and energy savings, waste, recycling, transportation, etc.), quality of life issues have been considered in all definitions of sustainable cities. In addition, developing more sustainable cities requires not only improving the biotic aspects of urban life but also pursuing the social aspects of city life, including people's satisfaction with, experiences and perceptions of the quality of their everyday environments as well as quality of life issues, which are central to everything.

Urban areas are considered to be a key component of sustainable cities, and the creation of more sustainable urban areas is essential to sustainability (Ozdemir, 2007) [58]. Sustainable areas are defined as those created to support sustainable living, with a primary focus on economic, social, and environmental sustainability (Huseynov, 2005) [59]. This is of distinguished importance for urban green spaces, which tend to signify and symbolize a diverse set of ideals regarding the city's identity, including its history and culture on one hand and its local economic viability on the other. Accordingly, the urban landscape is considered to be very positively linked to sustainability policies (Beck, 1992 [60]; Sachs, 1995 [61], Ferris, et al., 2001 [62]; Loureset et al., 2007 [63]). Not only in theory, but the empirical research also has highlighted the role of urban landscapes in the environmental, aesthetic, psychological, social, and economic aspects of urban life (Grahn, 1985 [64]; Burgess et al., 1988 [65]; Conway, 2000 [66]; Gehl and Gemzoe, 2001 [67], DeGraaf, 2003 [68]; Chiesura, 2004 [69]; Chang, 2005 [70]; Rosenberger et al., 
2009 [71]; Peters, 2010 [72]). Once more, urban green spaces due to their beneficial services stand out as key components in urban sustainability (IUCN, 1991) [73] and one possible step to creating sustainable urban environments (Jongman, 1995 [74]; Jongman et al., 2004 [75]; Opdam et al., 2006 [76]; Zhang and Wang, 2006 [77]). Accordingly, aspects such as the "amount of urban green spaces per inhabitant," "public parks," and "recreation areas" are considered to be of significant strategic importance for improving quality of life (Miller, 1988 [78]; Grey, 1996 [79]; Teal et al., 1998 [80]) and, making a city livable, pleasant, and attractive for citizens (Chiesura, 2004) [69].

The protective factors of nature towards the physical, psychological, and social health of people and communities have been emphasized by various researchers (Takano et al., 2002 [81]; St Leger, 2003 [82]; Maller et al., 2005 [83]). In this regard, growing empirical evidence indicates that the presence of natural resources (e.g., urban parks, gardens and forests, and green belts) and components (e.g., trees and water) in urban contexts contributes to residents' well-being and quality of life in many ways. Trees, the predominant component of urban green spaces, are considered due to their significant role in wind and noise filtration, air purification, and the reduction of pollution costs. Trees' aesthetic and relaxation values increase the attractiveness of cities and encourage tourism, subsequently generating employment and revenues (Chiesura, 2004) [69] and benefiting cities economically. From physical and psychological points of view, natural scenes or elements foster stress recovery (Ulrich, 1981 [84], Rostami et al., 2014 [85]) by evoking positive feelings and reducing negative emotions. By blocking stressful thoughts, trees provide a sense of peacefulness and tranquility (Kaplan, 1983) [86], resulting in mental (Hartig et al., 1991 [87]; Conway, 2000 [66]) and physical health (Godbey et al., 1992) [88]. Therefore, urban nature and daily outdoor recreation opportunities seem to be the main factors that enhance local people's everyday well-being (Eronene et al., 1997) [89], even if those opportunities have been used only occasionally (Thompson, 2002 [90]; Tinsley and Croskeys, 2002 [91]; Chiesura, 2004 [69]). From a social point of view, nature can encourage the use of outdoor spaces, bring people together, weave together parts of a city into a cohesive whole, and increase social integration and interaction among neighbors (Coley et al., 1997) [92], which lead to trust, mutual understanding, shared values, and supportive behaviors (Loures et al., 2007) [63]. By providing social, psychological, and physical services, natural areas enrich human life with meaning and emotions, which are crucial to achieving livable modern cities and the well-being of urban dwellers. All of these factors are considered key components of sustainable cities.

Despite all above mentioned benefits of urban green spaces, little is known about historical urban green spaces and the benefits they could provide for their users. This paper analyzed a number of historical Persian gardens, which are still actively used by urban residents, in order to respond to the following research questions: firstly, what benefits do historical urban green spaces provide for their users? Secondly, what is their importance with regard to citizens' well-being and city sustainability?

\section{Material and Methods}

The study applied sequential mixed methods that collected both quantitative and qualitative data, during the study, (Creswell, 2002 [93]; Creswell, 2003 [94]; Creswell and Creswell, 2009 [95]; Puhakka et al., 2013 [44]) and combines the collective strength of multi-methods with triangulation (Decrop, 1999 [96]; Hunt and Stronza, 2009 [97]). The data were collected from three primary sources: on-site surveys, 
semi-structured interviews and behavioral observations. The study began by collecting quantitative data from surveys to generalize results to a population, followed by unobtrusive behavioral observation and qualitative data obtained from semi-structured interviews that collect detailed responses from participants. From the mixed-method strategy, the study aimed to provide some generalization of the rich information obtained from the respondents of surveys, the participants of interviews, and various observation techniques. Table 1 provides an overview of the study's research method and strategies of inquiry.

Table 1. Overview of research method and strategies of inquiry (T: Tabriz, I: Isfahan, S: Shiraz, K: Kerman).

\begin{tabular}{|c|c|c|c|c|c|c|c|}
\hline \multirow{2}{*}{$\begin{array}{l}\text { Research } \\
\text { Approach }\end{array}$} & \multirow{2}{*}{ Strategies of Inquiry } & \multirow{2}{*}{ Techniques } & \multicolumn{5}{|c|}{ Respondents/Participants (n) } \\
\hline & & & $\mathbf{T}$ & I & $\mathbf{S}$ & $\mathbf{K}$ & Total \\
\hline \multirow{3}{*}{$\begin{array}{l}\text { Mixed } \\
\text { Method }\end{array}$} & Questionnaire Surveys & $\begin{array}{l}\text { Self-administered questionnaire } \\
\text { including: closed-ended with a } \\
\text { few open-ended questions }\end{array}$ & 100 & 152 & 112 & 100 & 464 \\
\hline & Semi-structured Interviews & Semi-structured questions & 10 & 10 & 10 & 10 & 40 \\
\hline & Behavioral observations & $\begin{array}{l}\text { Unobtrusive observations } \\
\text { (types and length of activity, } \\
\text { location, age group and size) }\end{array}$ & 60 & 72 & 60 & 50 & 242 \\
\hline
\end{tabular}

\subsection{Case Study of Historical Persian Gardens}

Historical Persian gardens, in the hot arid regions of Iran, are one of the most well-known traditional methods of achieving beauty and aesthetics and compensating for poor humidity, and creating a sustainable micro climate for human living. Persian gardens are examples of ancient gardens, which may have originated as early as $4000 \mathrm{BC}$, during the Achaemenid dynasty, when the idea of an early paradise spread throughout Persia. The etymology of term for Persian garden "Pardis" is derived from the Avestan word "Paridaeza", with the old Persian "Paridaida" meaning "walled". Such gardens are surrounded by walls to provide relief from the extremes of the climate and sand storms. As a paradise on earth, they provide an area of protected relaxation in a variety of manners. In Persian gardens, secular extremity is upgraded to spiritual extremity. From among the appearances and diverse existences of nature, different elements such as soil, water, light, and even windflaws are used in the establishment of gardens, which can be used as places of spiritual solace.

To arrange and create the space of the garden and achieve clear views, the mathematical concepts and geometrical structures of "Chahar Bagh" are considered. "Chahar Bagh" or "Four Garden" is the outstanding scheme of Persian gardens that became the core design for subsequent formal Iranian gardens. This rectangular cross-plan derived from fundamental layout of all Persian Architecture "chahâr-tagh" which divide a space into four quadrants. "chahâr-tagh" originated in the Fifth Century $\mathrm{BC}$, and founded in the Parthian constructions which linking the square plan of the Zoroastrian temple. This four-part archetypal element transposed into other fields of artistic expression as well as Persians' garden design. This type of cross plan, include two vertical axis in which one axis may be longer than the other always divides the garden into four main sections (Wilber, 1979) [98] and influences other garden systems such as irrigation, cultivation, disposition, and prospect systems. The scheme was first apparent in "Pasargadae" (The Royal Garden of Cyrus the Great, the king of Achaemenian dynasty) in 
$550 \mathrm{BC}$, and was conceived to symbolize Eden and the four Zoroastrian elements of sky, earth, water, and plants. The diversity of Persian gardens evolved through adaptation to different climate conditions, but the principle of design, "Chahar Bagh", remained and continued in different eras, even in Islamic and Mogul times.

In the 11th century, Persian gardens established a complex relationship with the city and became a part of public places. However, the usage of the aforementioned principle less considered, and the pattern was replaced with an imitation of European gardens, primarily French ones. The French "Parterre" — which is a formal garden constructed on a level surface, consisting of planting beds, typically in symmetrical patterns, separated and connected by gravel pathways - are not considered to be appropriate in the context of Iranian culture and climate. Consequently, the frequencies of usage of these spaces by the urban inhabitants have diminished. Based on recent studies, people are not eager to use the parks frequently; however, there is a high degree of preference for involvement with natural settings for contemplation, observing landscape views, and being close to trees and shaded areas (Hami et al., 2011) [99] in order to escape from boredom, reduce their depression, and increase their performance and consequently have better mental, psychological and social status (Khosravaninezhad et al., 2011) [100]. Hence, urban parks in Iran can be suggested to have issues regarding low usability rate and vandalisms (Hami et al., 2011) [99]. Nonetheless, existing historical Persian gardens are still actively used by urban residents. However, there is no official statistics about the number of visitors, but records of Tourist Attraction Organization indicates that at least half million people visit each gardens annually with largest proportion, around 20-30 thousand person per day, during Iranian New year (April) and summer holidays. To highlight urban green spaces' importance with regard to environmental sustainability and citizens' well-being, this study analyzes a number of these gardens.

\subsection{Study Areas}

Four historical and traditional cities of Iran, namely Tabriz, Isfahan, Shiraz, and Kerman, were chosen due to their historical backgrounds and the existence of historical Persian gardens that are being actively used. To find the most popular and memorable gardens among the existing samples, a pilot test was undertaken based on residents' preferences. The pilot test concluded that the El-Goli Garden in Tabriz (Figure 2A), the Hasht Behesht Garden/Bagh-e-Bolbol (Figure 2B) in Isfahan, the Eram Garden in Shiraz (Figure 2C) and the Shahzdeh Garden (Figure 2D) in Kerman were the most frequented. Although the gardens seemed dissimilar in style, there were no structural differences in the four gardens because of the principle of design of Persian gardens, chahar bagh. That is, they exemplify the diversity of Persian garden designs, which have evolved and adapted to different climate conditions while retaining principles rooted in the times of Cyrus the Great. Table 2 summarizes the gardens' characteristics. 

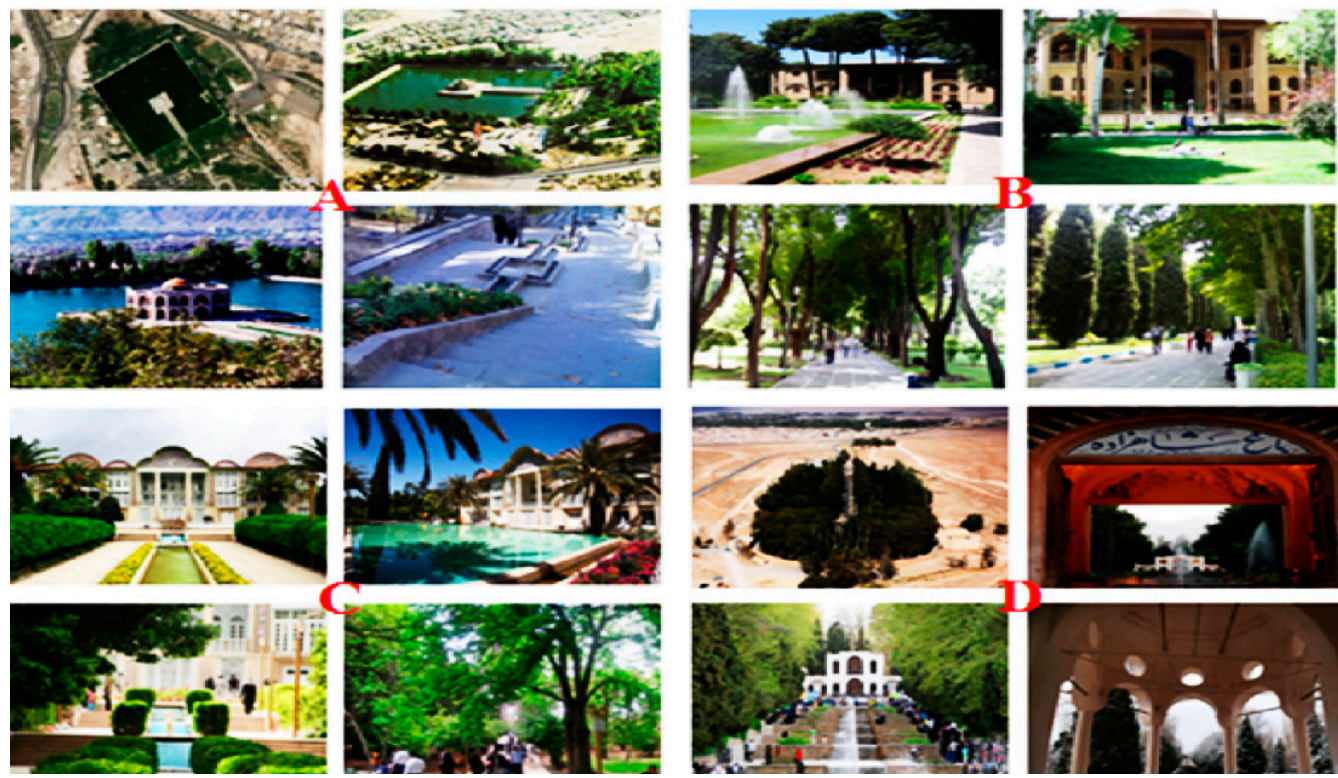

Figure 2. Some Photos of the Gardens; (A) El-Goli Garden, (B) Hasht Behesht Garden, (C) Eram Garden, (D) Shahzadeh Garden.

Table 2. Gardens' characteristics.

\begin{tabular}{|c|c|c|c|c|}
\hline & & Literally Means: & & \\
\hline \multirow{2}{*}{$\begin{array}{l}\text { Tabriz } \\
\text { 4th largest City } \\
\text { of Iran }\end{array}$} & El-Goli/or Shah Goli & & 18th Century & $54,675 \mathrm{~m}^{2}$ \\
\hline & \multicolumn{4}{|c|}{$\begin{array}{l}\text { El-Goli Garden is a: } \\
\text { Water garden with an artificial lake (about } 700 \mathrm{~m}^{2} \text { ) Covered by raising artificial terraces that are } \\
\text { concealed beneath plantings of poplars and willows }\end{array}$} \\
\hline \multirow{2}{*}{$\begin{array}{l}\text { Isfahan } \\
\text { 3rd largest City } \\
\text { of Iran }\end{array}$} & $\begin{array}{c}\text { Hasht Behesht/or } \\
\text { Bagh-e-Bolbol }\end{array}$ & $\begin{array}{c}\text { Eight Heaven/or } \\
\text { Nightingale Garden }\end{array}$ & 17th Century & $67,000 \mathrm{~m}^{2}$ \\
\hline & \multicolumn{4}{|c|}{$\begin{array}{l}\text { Hasht Behesht Garden is a: } \\
\text { Garden around Hasht Behesht palace. It was built in Safavid era as king palace. Today it is protected } \\
\text { by Iran's Cultural Heritage Organization }\end{array}$} \\
\hline \multirow{3}{*}{$\begin{array}{c}\text { Shiraz } \\
\text { 6th most } \\
\text { popular City of } \\
\text { Iran }\end{array}$} & Eram Garden & - & $\begin{array}{l}\text { 11th-12th century } \\
\text { Repaired in } \\
\text { 18th Century }\end{array}$ & $110,380 \mathrm{~m}^{2}$ \\
\hline & \multicolumn{4}{|c|}{$\begin{array}{l}\text { Eram Garden is a: } \\
\text { Garden that its origin layout with its quadripartite Persian structure was laid in 11th-12th century. } \\
\text { Eram Garden have been restored and repaired by the Zand Dynasty (1750-1794). Eram is the } \\
\text { Persianized version of the Arabic word "Iram" meaning heaven in the Qur'an. Eram Garden therefore } \\
\text { is so called for its aesthetic attractions resembling "heaven." Today Eram Garden is considered as } \\
\text { Botanical Garden (established 1983) of Shiraz University and categorized as World Heritage Site, and } \\
\text { protected by Iran's Cultural Heritage Organization as well. }\end{array}$} \\
\hline & Shahzadeh Garden & Prince's Garden & 18th Century & $55,000 \mathrm{~m}^{2}$ \\
\hline $\begin{array}{l}\text { Kerman } \\
\text { One of oldest } \\
\text { City of Iran }\end{array}$ & \multicolumn{4}{|c|}{$\begin{array}{l}\text { Shahzadeh Garden: } \\
\text { It was the summer residence of Qajar princes. It consists of an entrance structure and gate at the lower } \\
\text { end and a two-floor residential structure at the upper end. The distance between these two is } \\
\text { ornamented with water fountains that are engine by the natural incline of the land. The garden, now } \\
\text { categorized as one of UNESCO World Heritage Site. }\end{array}$} \\
\hline
\end{tabular}




\subsection{Pilot Test}

In addition, before the actual final on-site surveys and semi-structured interview were carried out, another preliminary round of questions concerning the parameters of the study were pilot-tested on a small random sample of residents $(n=15)$ in Tabriz. The pilot study came in the form of survey interviews, and preliminary observations were undertaken to explore the experience of residents using the garden and to investigate the possibility of undertaking further research on the parameters identified in the reviews. The pilot survey tested the structure of the questions in the questionnaire, the sample group and the timing. The results revealed the need for certain alternations to be made to the actual survey. Thus, some questions were changed, removed, or added to create a proper survey.

\subsection{Final Survey}

The final survey was conducted in July, 2010 which was personally administered by the researchers. This research conducted sequential mixed-method which uses the information from quantitative and qualitative data to provide a comprehensive analysis of the research problems and interpret the overall findings. The questionnaires addressed a broad range of issues covering interrelation of four main determinants including: (1) salient characteristics and attributes of gardens, (2) users' perceptual responses, (3) and their experiential contact with the gardens and, (4) its effects on their mood change and self-reported. In addition, response formats were either closed (multiple choices) or open-ended. Although the questionnaire and interviews were in Farsi, Iran's national language, the responses were later translated and transcribed into English for analysis. In addition, effort was taken to ensure that the original meaning of the dialog was not lost or compromised. Descriptive statistics and content analysis were used to analyze the data and triangulation underpinned the examination of the relationships. Detailed discussions about the process of collecting data will be presented in the following sections.

\subsubsection{Self-Administered Questionnaire}

For the final survey, a self-administered questionnaire was the primary method for obtaining responses from visitors to gardens residing in the studied cities (Tabriz, Isfahan, Shiraz, and Kerman). Respondents were randomly selected among onsite visitors of gardens from various age groups at different hours of day, usually 6-9 am and 5-8 pm when the gardens were more crowded, and in different parts of the gardens during weekdays and weekends. In addition, personal attributes such as gender, occupation, and educational background were considered. Attempts were made to ensure a balanced ratio of all variables. Respondents were asked to complete the questionnaire and return the completed survey during their stay in the gardens so that the answers would reflect their immediate experiences. The questions were either closed (multiple choice) or open ended. The questionnaires addressed a broad range of issues, from motives for visiting the gardens and their activities during visit periods to their feelings towards the gardens. In some parts of questionnaire, open-ended questions for better understanding about users' view points and perspectives were adopted. Finally, 500 questionnaires were returned that among them 464 that completely filled out were considered in this study. 


\subsubsection{Semi-Structured Interview}

Interviews surpass questionnaire at telling stories from participants' view point and provide rich descriptive details with quantitative results on the human context (Mehta, 2006) [101]. Hence, the study included a detailed semi-structured face-to-face interview with a few residents who randomly selected among interested participants. The basic structure of the questions was established as a guide during the interview administration. The interview script and questions were developed based on the pilot survey interview and survey questionnaire administered earlier on site. The interviews were carried out between $7 \mathrm{am}$ and $11 \mathrm{pm}$, spread out between weekdays and weekends. The main considerations in this regard were respondents' length of residency and frequency of visit. Totally, forty respondents, divided in to ten in each site, participated in the interview procedure. The time taken for the interview ranged from 30 minutes to one hour, with respondents spending an average of 50 minutes answering the questions. The interviewers took notes onsite as well as a means to quickly summarize the information received to help the researchers recall the details of the interview at a later date when processing the interview recordings.

\subsubsection{Behavioral Observation}

Behavioral observation has been mentioned as a meaningful way of measurement of the environmental perception of individuals (Shafer, 1969) [102]. It entails observation records or field-notes details. It is a systematic noting and recording of events, behaviors, and artifacts (objects), a nonjudgmental and concrete description of what has been observed in the setting to discover social interaction in the social setting that chosen for the study (Marshal and Rossman, 2010) [103]. That is, people and settings are dependent to each other and events in the world involve characteristics of people and of the settings in which they are embedded. Questions like "where", "who", and "what" in behavioral observation enables the researcher to identify types of activities and behavioral patterns and interpret the interaction between users and the properties and attributes of the setting they encountered. That is, it provided information on what participants do in the spaces and where they sit, gather, socialize or walk and stand, and what facilities they used, either as a part of their daily necessary activities and/or for optional and leisure activities (Mehta, 2006) [101]. Indeed, a more detailed look at the role of streets, parks and other open space typologies (Gehl and Gemzoe, 2001) [67] might have yielded greater insight into the function each might and should perform (Thompson, 2002) [90]. Accordingly, behavioral observations were used as a complementary method. Daily observations were carried out in the morning, noon and evening over weekdays and weekends to determine and classify how people use gardens, what spaces are preferred most by users, and what physical characteristics of gardens affect their choices. The activities in which people engaged were recorded on coding sheets based on age group, gender, type of activity, whether the participant was alone or with others, and when and where the identified activities occurred (Bradley and Millward, 1986) [104]. All the activities were recorded under specific categories (sitting, walking, relaxing, reading book or newspaper, talking each other, eating, exercising or playing sports, family picnic) and described in detail where necessary. 


\section{Results}

In total, 464 respondents took part in the questionnaire in all four cities. This sample included 100 respondents $(21.55 \%)$ in Tabriz, $152(32.32 \%)$ in Isfahan, $112(24.13 \%)$ in Shiraz, and $100(21.55 \%)$ in Kerman. In total, the male gender constituted more respondents $(59.1 \%)$. The age classes ranged from below 10 years old to over 60 . The 20-30 age groups were the most predominant $(57.3 \%)$. Most of respondents had university degrees and could be categorized as students. The mean amount of time spent living in the studied cities was almost 20 years (Standard Deviation $(\mathrm{SD})=14.944)$.

\subsection{Motives for Visiting Gardens}

To evaluate gardens' attractiveness, respondents were asked about the reasons they were encouraged to visit the gardens. They were asked why they visited these gardens. The frequency output of the variables shows that the nature of garden and vegetation are the most important aspects motivating more than half of all respondents (55.6\%) and it followed by gardens' beauty, which motivated $49.1 \%$ of all respondents (see Table 3). Fascinating nature of gardens (34.9\%) and their restorativeness power $(32.1 \%)$ as well as open views and easy accessibility (25\%) mentioned as the other effective reason of visits. The findings also indicate that almost $20 \%$ of respondents visit the gardens because of its silence and visual diversity. Reasons such as the silence of the gardens highlight the need for solitude and distance from daily pressures.

Table 3. Respondents' motives of visitations (based on questionnaire survey).

\begin{tabular}{lccccc}
\hline Reasons & Tabriz & Isfahan & Shiraz & Kerman & Total \\
\hline (1) It is crowded. & $17 \%$ & $10.5 \%$ & $6.2 \%$ & $35 \%$ & $9.3 \%$ \\
(2) It is quiet. & $21 \%$ & $18.4 \%$ & $27.7 \%$ & $16 \%$ & $20.7 \%$ \\
(3) Its open view. & $37 \%$ & $23.7 \%$ & $25.9 \%$ & $24 \%$ & $27.6 \%$ \\
(4) Its beauty. & $58 \%$ & $34.9 \%$ & $55.4 \%$ & $55 \%$ & $49.1 \%$ \\
(5) It is fascinating. & $37 \%$ & $21.1 \%$ & $46.4 \%$ & $41 \%$ & $34.9 \%$ \\
(6) It is restorative. & $39 \%$ & $24.3 \%$ & $36.6 \%$ & $32 \%$ & $32.1 \%$ \\
(7) It is a novel place. & $28 \%$ & $8.6 \%$ & $19.6 \%$ & $18 \%$ & $17.2 \%$ \\
(8) It is a meeting place. & $18 \%$ & $17.1 \%$ & $25.9 \%$ & $4 \%$ & $16.6 \%$ \\
(9) Its visual diversity. & $22 \%$ & $10.5 \%$ & $23.2 \%$ & $30 \%$ & $20.3 \%$ \\
(10) Its nature and vegetation. & $66 \%$ & $45.4 \%$ & $49.1 \%$ & $68 \%$ & $55.6 \%$ \\
(11) Its harmony and order. & $13 \%$ & $17.1 \%$ & $17.9 \%$ & $24 \%$ & $17.9 \%$ \\
(12) Its cleanliness. & $25 \%$ & $27.6 \%$ & $24.1 \%$ & $14 \%$ & $23.3 \%$ \\
(13) It is far from my living area. & $13 \%$ & $5.3 \%$ & $5.4 \%$ & $0 \%$ & $5.8 \%$ \\
(14) It is close to my living area. & $17 \%$ & $9.9 \%$ & $11.6 \%$ & $20 \%$ & $14 \%$ \\
(15) It is accessible & $32 \%$ & $37.5 \%$ & $25.0 \%$ & $4 \%$ & $26.1 \%$ \\
(It placed in very good position in the city). & & & & & \\
(16) It is familiarity & & & & & \\
(I am familiar with it and can wander & $27 \%$ & $12.5 \%$ & $8.9 \%$ & $2 \%$ & $12.5 \%$ \\
without being lost). & & & & & \\
(17) It is a representative place of city. & $34 \%$ & $13.8 \%$ & $17.0 \%$ & $25 \%$ & $21.3 \%$ \\
(18) I had a sense of attachment to this place. & $23 \%$ & $15.8 \%$ & $18.8 \%$ & $20 \%$ & $12.5 \%$ \\
\hline
\end{tabular}


Another aspect that motivates around $1 / 4$ of residents' visitations is the consideration of gardens as a representative place of the city $(21.3 \%)$. They also mentioned that they have a sense of attachment $(12.5 \%)$ to these gardens. In addition, the consideration of the gardens as a novel places (17.2\%) and meeting place $(16.6 \%)$ constituted other reasons that encouraged people to visit the gardens. Close proximity and familiarity with the gardens' area are other reasons that follow in decreasing frequency.

A content analysis of the interview question regarding the reason for visiting also verifies the results. In interview checklists, respondents were asked to discuss "why they choose this garden for visitation". Analysis reveals that the amount of greenery and vegetation, especially trees, in the garden is the most frequent motive for visits (75\%). The beauty of the garden, calmness and tranquility, and being away for a while from daily stresses were mentioned as the second most frequent reasons for visits. Moreover, other factors such as gardens' symbolic aspects, gardens' location, the distance of users, and their memories regarding gardens were also found to be motivations among the interviewees. Even though, the gardens frequently symbolized as historical $(52.8 \%)$ but, content analyses of the responses revealed that respondents mostly described gardens as their city symbol and identity as well. They believed that gardens as their city symbol can resemble their culture, civilizations, and even their identity; as such, Tabriz respondents emphasized on garden as signifying of their city and even their identity as Azari ethnic.

Performance of cross-tabulation between gender and most frequently cited motives revealed significant differences between males and females and gardens' beauty $(p=0.031)$. The beauty of the gardens was the second most cited motive which considered more by $61.57 \%$ of females compare to males $51.45 \%$. Further, various age-related differences were found (Table 4). Motives such as gardens' beauty and nature more frequently influenced 20- to 30-year-olds to visit the gardens compared to other age groups. In addition, the results indicate that those below 10 and those over 60 were not motivated by gardens' restorative effects. It seems that they mostly visited the gardens to be with others.

Table 4. Motives-age cross-tabulation (Chi-square), significance $<0.05$.

\begin{tabular}{ccc}
\hline Motives & Total Percentage & Test Results \\
\hline Nature and Vegetation & $55.6 \%$ & $\begin{array}{c}\chi^{2}=17.556 \\
p=0.008\end{array}$ \\
\hline Gardens' Beauty & $49.1 \%$ & $\begin{array}{c}\chi^{2}=10.183 \\
p=0.047\end{array}$ \\
\hline Gardens' Fascination & $34.9 \%$ & $\begin{array}{c}\chi^{2} \\
p=12.355 \\
p=0.028\end{array}$ \\
\hline Gardens' Restorativeness Power & $32.1 \%$ & $\begin{array}{c}\chi^{2}=12.783 \\
p=0.026\end{array}$ \\
\hline
\end{tabular}

Another research inquiry identified predominant physical features of historical Persian gardens that could affect people's presence. Respondents were asked to rank the following options: open views, trees, shadows from trees, shrubs, flowers, still water (pool or lake), streaming water, and traditional buildings that exist in the gardens. The findings indicate that all features were ranked as essential with different frequency. A frequency analysis (Figure 3) showed that shadow from trees was the most effective feature. $36.2 \%$ of respondents chose tree features, but almost $43.5 \%$ of respondents believed that shadows from trees are the most important feature that encourages people to use gardens, especially during summer months. The next most important feature according to respondents was water. 
Respondents believed that water in the form of streams $(40.3 \%)$ or still water $(39.3 \%)$ can affect their mood. They mentioned that the existence of water and, beyond this, the sound of streaming water influence their calmness and reduce stress. Another physical feature that was important for $38 \%$ of respondents was existence of historical buildings in the gardens. The other features, such as flowers, open views and shrubs, follow in decreasing frequency.

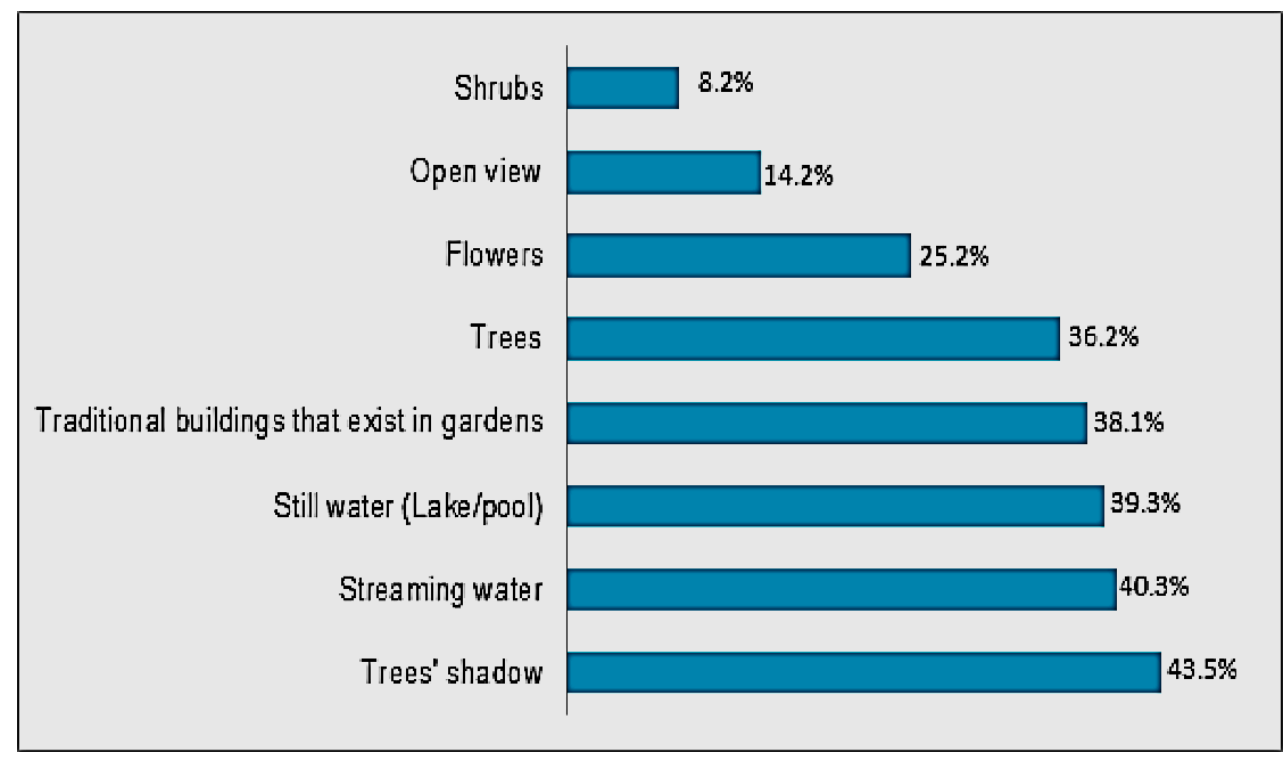

Figure 3. Effective physical features of gardens.

\subsection{Functional Aspects of Gardens}

It has long been argued that physical settings, activities, and meanings are interrelated (Gehl, 2001) [105]. Based on Dempsey (2006) [106], social activity, which is pivotal for sustainability, is more likely to occur in high-quality physical environments in theory, policy, and practice. Common norms and codes of behavior define a sense of community and place attachment, which is also a key component of sustainability. Therefore, the functional aspects of the gardens were considered to examine gardens' social ability. To attain a fuller understanding, the amount of time visitors spent in the gardens was also measured. An analysis of the length of time spent in the gardens revealed that people stayed in the garden for at least half an hour. Most respondents (39.2\%) preferred to stay in the gardens 1-2 hours or even a whole day. This result could signify the comfort level and attractiveness of gardens, and their ability to fulfill the respondents' needs.

To evaluate the social activities that take place in the gardens, respondents were asked to choose their experiences and activities during visits to the garden with the following options: I have come to visit this garden for passive recreation (refreshment, calmness and relaxation), to sit alone, to wander and walk, for a family picnic, to be with others, to exercise, to observe nature, and to be a part of nature. A frequency analysis of people's activities in the gardens revealed that passive recreation was the most common experience of visitors (see Table 5). 57.5\% of respondents came and stayed in the gardens for passive recreation. Observing nature is the second most common experience and it followed by considering garden visits as being a part of nature (27.2\%), which reflects once more the importance of nature. 
Social activities such as family picnics $(28.2 \%)$ and being with others $(23.7 \%)$ reveal the social aspect of gardens, encouraging people to be with one another. Activities such as seeing others (11.2\%), being seen by other people (20.5\%), and sitting in some part of the garden $(20 \%)$ constitute other social aspects of the gardens. Other activities such as exercising and walking follow in decreasing frequency and were considered less by respondents.

Table 5. Experiences and activities in the gardens.

\begin{tabular}{cccccc}
\hline Activities & Tabriz & Isfahan & Shiraz & Kerman & Total \\
\hline $\begin{array}{c}\text { For passive recreation } \\
\text { (refreshment, relaxation and calmness) }\end{array}$ & $63 \%$ & $44.1 \%$ & $70.5 \%$ & $58 \%$ & $57.5 \%$ \\
\hline To be with others. & $28 \%$ & $29.6 \%$ & $23.2 \%$ & $11 \%$ & $23.7 \%$ \\
\hline For sitting. & $23 \%$ & $22.4 \%$ & $24.1 \%$ & $9 \%$ & $20 \%$ \\
\hline To see others & $15 \%$ & $13.2 \%$ & $13.4 \%$ & $2 \%$ & $11.2 \%$ \\
\hline For walking and wandering & $6 \%$ & $6.6 \%$ & $5.4 \%$ & $0 \%$ & $4.7 \%$ \\
\hline Others see me & $34 \%$ & $17.8 \%$ & $25.9 \%$ & $5 \%$ & $20.5 \%$ \\
\hline For family picnic & $48 \%$ & $13.2 \%$ & $17.0 \%$ & $44 \%$ & $28.2 \%$ \\
\hline To do exercise & $24 \%$ & $9.2 \%$ & $2.7 \%$ & $5 \%$ & $9.9 \%$ \\
\hline To observe nature & $52 \%$ & $36.8 \%$ & $55.4 \%$ & $45 \%$ & $46.3 \%$ \\
\hline To be in a part of nature & $27 \%$ & $20.4 \%$ & $25.9 \%$ & $39 \%$ & $27.2 \%$ \\
\hline
\end{tabular}

More detailed observations indicate the breakdown of explicit activities (aggregation (10\%), talking (14\%), sitting (12\%) playing chess (18\%), studying with friends (20\%), family picnics $(26 \%)$ ) occurring under shadow trees $(30 \%)$, in grass areas $(18 \%)$, or near water features $(36 \%)$ (see Figure 4$)$. The amount of time visitors spent in common spaces was strongly related to the presence, location, and number of trees and the presence of water features.
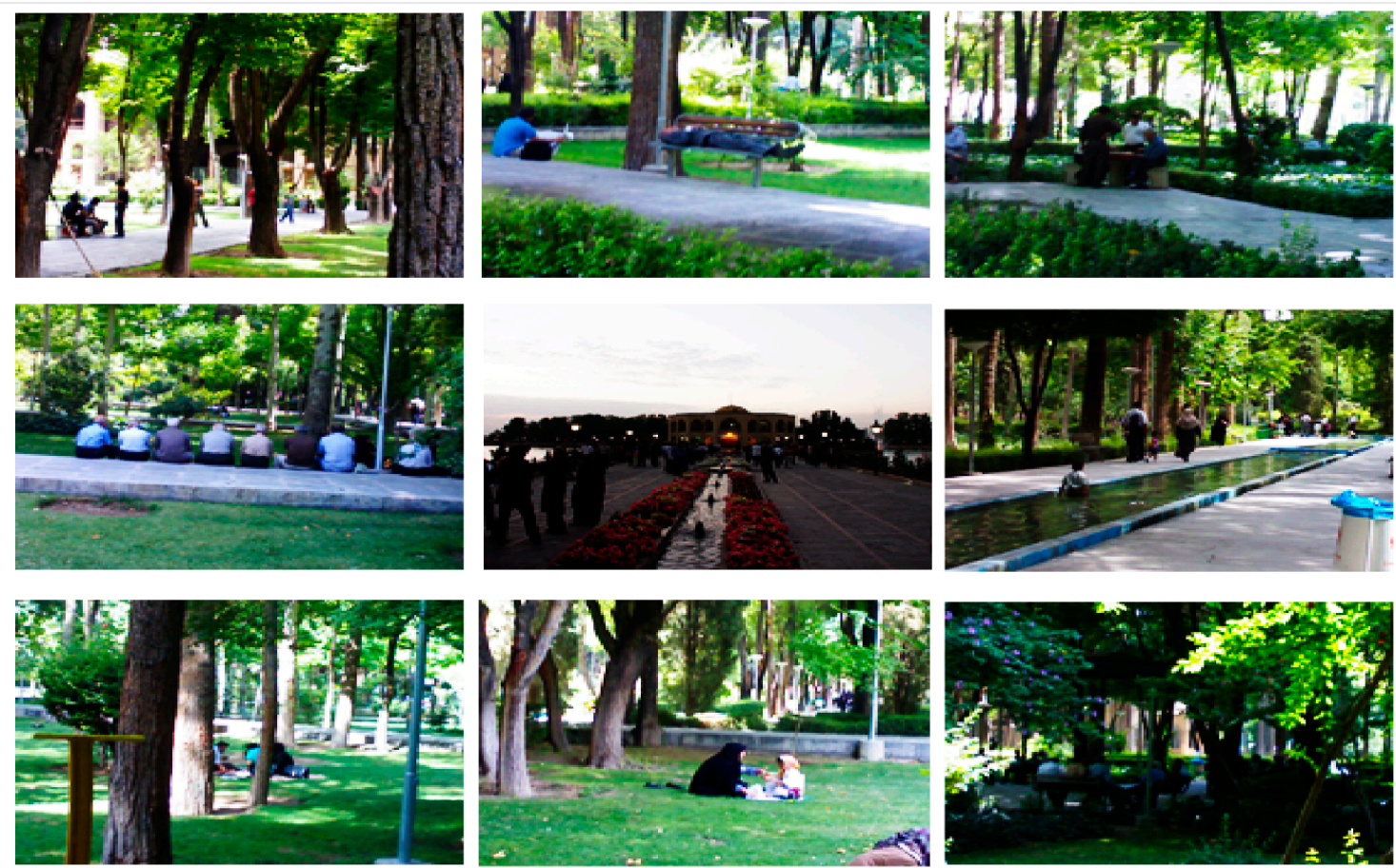

Figure 4. Samples of users' activities during garden visitation. 
Further, significant gender-related differences with regard to the frequency of activities were found $(p<0.05)$. Recreation as the most predominant experience of residents during garden visits was found significantly more related to males compared to females $(p=0.030)$. Regarding age cross-tabulation and activities, some significant differences were also found (Table 6). Almost all age groups except those below 10 years of age visit the gardens for recreation $(p=0.000)$. For those below 10 years of age, family picnics were the most common activities. Activities such as family picnics and being with others were more common for those below 40 compared to those over 60 .

Table 6. Activities-age differences (Chi-square), * significance $<0.05$.

\begin{tabular}{ccc}
\hline Activity & Total Percentage & Test Result \\
\hline Recreation & $57.5 \%$ & $\begin{array}{l}\chi^{2}=22.823 \\
p=0.000 *\end{array}$ \\
\hline Nature Observation & $46.3 \%$ & $\begin{array}{l}\chi^{2}=8.271 \\
p=0.142\end{array}$ \\
\hline Family Picnic & $28.2 \%$ & $\begin{array}{l}\chi^{2}=22.375 \\
p=0.000 *\end{array}$ \\
\hline To be in a piece of nature & $27.2 \%$ & $\begin{array}{l}\chi^{2}=18.325 \\
p=0.014 *\end{array}$ \\
\hline To be with others & $23.7 \%$ & $\begin{array}{l}\chi^{2}=21.148 \\
p=0.003 *\end{array}$ \\
\hline Others see me & $20.5 \%$ & $\begin{array}{l}\chi^{2}=21.128 \\
p=0.002 *\end{array}$ \\
\hline Sitting & $20.0 \%$ & $\begin{array}{l}\chi^{2}=9.253 \\
p=0.118\end{array}$ \\
\hline To see others & $11.2 \%$ & $\begin{array}{l}\chi^{2}=21.843 \\
P=0.004 *\end{array}$ \\
\hline Doing exercise & $9.9 \%$ & $\begin{array}{l}\chi^{2}=21.958 \\
p=0.007 *\end{array}$ \\
\hline Walking & $4.7 \%$ & $\begin{array}{l}\chi^{2}=18.123 \\
p=0.014 *\end{array}$
\end{tabular}

\subsection{The Emotional Dimension of the Garden Experience}

Based on Cantrill and Senecah (2001) [107], emotional attachment to a place is created through firsthand interaction between humans and the place and defines a sense of place. Thus, the researchers were interested in exploring the emotional dimension of nature based on experiences. To explore the emotional aspects of gardens, respondents were asked to answer the following question: "What feelings do gardens evoke in you?" Some options were given (i.e., safety, freedom, comfortableness, happiness, calmness and tranquility, memories and remembrance, improved health, the feeling that you are closer to nature, and the feeling that you are different) and a space was provided for their description. A frequency analysis of the answers about the experienced feelings (Figure 5) shows that the "Calmness and tranquility" answer is the feeling most frequently cited by respondents, accounting for $63.5 \%$ of the answers. $38.4 \%$ of respondents mentioned that during their garden visits, they experienced a sense of being closer to the nature. Reminiscing (53.7\%) stands out as the second most important feeling evoked 
in the gardens. It encompasses respondents' pleasing memories (26.1\%), previous memories (15.3\%), and childhood memories (12.3\%). Happiness is another feeling that occurs during garden visitations and accounts for almost $38 \%$ of the answers. It is followed by feelings such as comfortableness $(25.4 \%)$ and improved health (19.0\%). Feelings of freedom and safety follow in decreasing frequency. The feeling that "I am different in this garden" was considered the least by respondents (5.2\%).

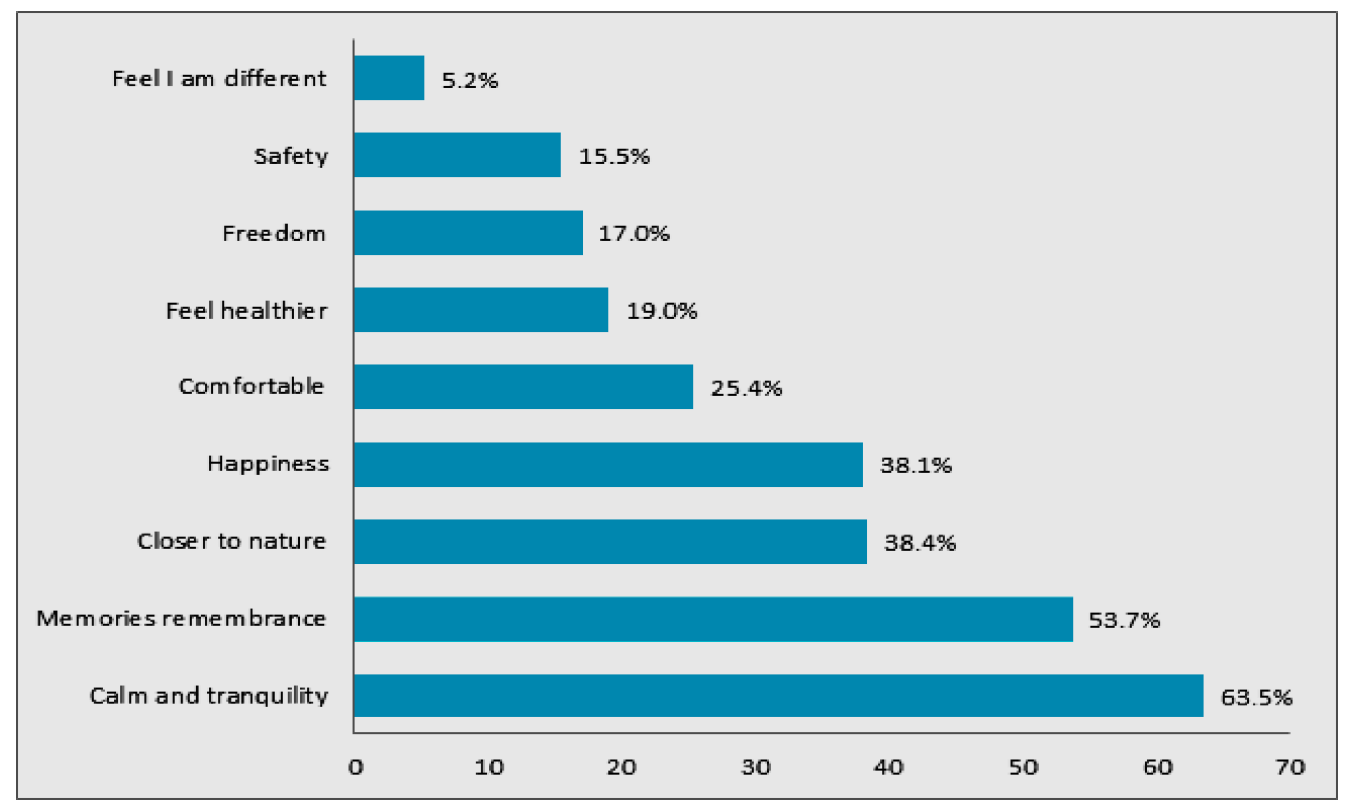

Figure 5. Feelings and emotional experiences.

\subsection{Garden Visitation and Well-Being}

The importance of parks, gardens, and urban green spaces in stress reduction and the presentation of health recovery opportunities have already been uncovered with the primary research of Ulrich (1983 and 1984) [108,109], Kaplan (1989, 1992 and 1995) [110-112], and Marcus and Barnes (1999). The results for visitors of the studied areas indicate that individuals who used urban green spaces often were much more likely to report good health compared to non-users (Grahn and Stigsdotter 2003 [113]; Nielsen and Hansen, 2007 [114]). This study offers a better understanding about the importance of garden experiences for people's health. Respondents were asked to rank the importance of visiting gardens with regard to emotional and physical disease like depression, sadness, tiredness, and sickness using a 1-5 points measurement scale (1, not important at all; 2 , not important; 3, important; 4, very important; 5, essential). A frequency analysis shows that responses range from important to essential (mean score: 2.5). Most respondents believed that visiting the gardens could reduce depression (94.4\%) and eliminate tiredness, which accounted for almost $90.9 \%$ of the answers. The results also show that sadness $(82.3 \%)$ and physical sickness $(77.6 \%)$ could be better during and after gardens' visitations. Overall, the findings reveal the natural effects on the betterment of both emotional and physical health issues, particularly emotionally related ones (Rostami et al., 2014) [85]. 


\section{Discussion}

The general social and cultural benefits of heritage have been noted by many previous scholars who have studied similar subjects. In this case, historic environments are widely acknowledged. Increasingly, heritages have been seen as a major component of social well-being and quality of life (Tweed and Sutherland, 2007) [4]. Cultural heritage is seen as a precious and irreplaceable resource, essential to personal identity and improving the quality of life (Lowenthal, 2006) [10]. According to Tate (Tate, 2005) [31], local identity refers to a sense of place or genius loci (pervading spirit of place). In addition, a positive sense of place creates a sense of attachment and it is considered as social sustainability indicator (Nash and Christie, 2003) [35]. A sense of attachment to place enhances the emotional bond to that place (Rogan, 2005) [36] and results in a sense of belonging to towns and society, which consequently enhances society's health. Such sense of place can be affected by the perceived quality of that place (Talen, 1999) [37] and manifest itself as a common norm and code of behavior (Kearns and Forrest, 2000) [38]. The social activities that take place in these gardens verify the effect of natural elements in encouraging the use of outdoor spaces (Coley et al., 1997) [92] and the role of natural features in increasing social integration and interaction among urban residents, thereby empowering a sense of place attachment or sense of community (Kuo, 2003 [115]; Kim and Kaplan, 2004 [116]; Dempsey, 2006 [106]), which leads to trust, mutual understanding, shared values, and supportive behaviors (Loures et al., 2007) [63]. In other words, presentations of social activity raise social interaction and integration and invoke trust and supportive behavior.

The empirical results of this study highlight the social benefits of historical Persian gardens. Activities such as family picnics and being with others indicate that, from a social point of view, residents consider gardens to be a source of urban nature and present opportunities for daily outdoor recreation, indicators that could enhance everyday well-being (Eronene et al., 1997 [89]; Rostami et al., 2014 [85]). The result also suggests the role of cultural heritage in social viability and cohesion (Vileniske, 2008) [5].

Beyond the physical and social aspects, gardens benefit residents psychologically. According to this study, the most common experience of residents in historical Persian gardens relates to passive recreation such as refreshment, calmness and relaxation. Historical Persian gardens serve as passive recreational facilities for urban populations. People visit the gardens primarily because they want to relax. More than half of the respondents mentioned passive recreation as an important need that is facilitated by the Persian gardens. This result highlights the psychological effects of nature, which evokes calmness and relaxation as well as stress reduction (Rostami et al., 2014) [85], where $46.3 \%$ of respondents considered natural observation as the second most important experience of the gardens. The result also verifies previous studies regarding people's need to experience nature (Kaplan and Kaplan, 1989) [110] and highlights the need for natural environments in urban contexts. In this regards, the natural aspects of the gardens and their components, primarily shades from trees and water are key features that affect visitors' presence and level of calmness. These results distinguish the natural aspects of the gardens (gardens' aesthetic attributes) as important factors that affect visitors' level of calmness and restorativeness (Hidalgo et al., 2006 [117]; Lothian, 1999 [118]; Nasar, 1983 [119]; Parsons and Daniel, 2002 [120]). That is, the tranquil atmosphere of the garden inspires reflection, meditation, and a general feeling of harmony between one's self and the surroundings. Consistent with the findings of previous researchers (Kaplan, 1989 [110]; Purcell et al., 2001 [121]; Ulrich, 2002 [122]; Karmanov and Hamel, 2008 [123]), 
respondents mentioned water and green space as the two most important physical features that contribute to changes in their mood. Shade trees moderate temperature and create a fresher ambience. They also encourage people to get together regardless of age group. In addition, the findings show that the experiences in gardens in cities are sources of a large array of positive feelings to people. Calmness and tranquility are the most important feelings experienced by residents in historical Persian gardens. Feelings of happiness, comfort, safety, freedom, and even improved health are frequently mentioned by respondents. The results confirm both the psychological health effects of nature on positive moods such as pleasure (Ulrich, 1981 and 1983 [84,108]; Rostami et al., 2014 [85]) and the reduction of negative effects such as anger and anxiety (Rohde and Kendle, 1994) [124]. All these emotional and psychological benefits contribute critically to the quality of human life, which in turn is a key component of sustainable development (Chiesura, 2004) [69].

For the aforementioned reasons, it can be suggested that historical Persian gardens can address urban residents' needs and raise people's daily well-being. Similarly, the historical fixation on the natural aspects of gardens has played a notable influencing role. The findings indicate that the feelings and emotions that are evoked in these gardens and perceived by people as very important to their health are due to the abundance of natural features in the gardens and residents' sense of attachment to those areas related to their historical associations. Gardens are historical and are perceived as valuable to urban living today, as well as the fact that they are old is one of the main reasons that people are attracted to them. Results indicate that historical Persian gardens tend to forge urban and even residents' identities. Beyond tangible heritage structures, however, respondents described a sense of local distinctiveness related to what Ashworth and Graham (Ashworth and Graham, 2005) [125] have described as the past's ability to convey timeless values. In all four cities, the sample gardens representatively dignified the entire city and served to reaffirm residents' feelings of identity and sense of belonging. In sum, historical Persian gardens, like many cultural landscapes, are significant to Iranian urban dwellers who have considered urban green spaces as city symbols and sources of local identity. These attitudes make gardens not only physically and visually noteworthy but also socially and culturally viable. Therefore, historical Persian gardens can be categorized as contributing to the sustainable cultural heritage, which potentially contributes to city sustainability.

\section{Conclusions}

In this study, the role of historical Persian gardens as a provider of social services and their importance for city sustainability has been addressed. Some of the results of a survey aimed at exploring the motives and perceptions of the visitors of four well-known historical Persian gardens have been presented. The following are some concluding remarks:

First, the study suggests that urban planning, with its contributions to tackling many detrimental environmental problems, which have recently been recognized as characteristic of crowded city centers and urban environments, can be considered as a premise towards creating sustainable urban living. The planning of urban green spaces and the revitalization of existing samples could result in improving the vast scope of environmental quality and subsequently serve as fundamental catalysts for major changes. Urban green spaces can bring people together; increase public congregation and interaction as well as 
increasing accessibility to public services and employment, which can be the main goals of sustainable urban policy.

In the context of this study, as natural urban areas, historical Persian gardens could be places for many social functions while addressing many of the psychological demands of urban living, which make these gardens a valuable municipal resource and a key ingredient for city sustainability. The memories and values that are associated with these historical gardens often create a sense of belonging and connectedness for a community, fostering social cohesion and inclusion through the power of place. In addition, heritage areas, such as these gardens, are cornerstones of urban revitalization and rehabilitation and could create local jobs and businesses and foster sustainable tourism and creative cities. Accordingly, it is suggested that sustainability indicators (i.e., socio-cultural, economic, environmental, and institutional) for an urban development should include more parameters related to green open spaces, particularly historical ones.

Furthermore, it is believed that public's participation and involvement in political governance as well as their needs and satisfaction are critical components of city sustainability. Their participation could bridge the gap between different pillars of sustainability and help urban communities articulate commonly shared values, which can be envisioned as reference criteria for more sustainable city strategies. The results also show that the physical activity that occurs in a place is related to physical and spatial indicators but also varies due to human characteristics, such as age, socio-demographics and people's perception of the environment. This variability should be taken into account by city planners and urban designers to fulfill the needs and expectations of all segments of the population.

\section{Acknowledgments}

The authors would like to thank Universiti Teknologi Malaysia Research Management Centre (RMC) and Center for the Study of Built Environment in the Malay World (KALAM).

\section{Author Contributions}

The research is designed and performed by Raheleh Rostami and Assoc. Hasanuddin Lamit. The data was collected by Raheleh Rostami and Seyed Meysam Khoshnava and Rasoul Rostami. Analyzes of data was performed by same authors and Muhamad Solehin Fitry Rosley. Finally, the paper is written by Raheleh Rostami. All authors read and approved the final manuscript.

\section{Conflicts of Interest}

The authors declare no conflict of interest.

\section{References}

1. United Nations. World Population Prospects: The 2005 Revision; Population Division of Department of Economic and Social Affairs: New York, NY, USA, 2005.

2. CHE. Report of the United Nations Conference on the Human Environment. Available online: http://www.un-documents.net/aconf48-14r1.pdf (accessed on 19 June 2007). 
3. World Commission on Environment and Development. Report of the World Commission on Environment and Development: Our Common Future. Available online: http://www.undocuments.net/our-common-future.pdf (accessed on 21 September 2015).

4. Tweed, C.; Sutherland, M. Built cultural heritage and sustainable urban development. Landsc. Urban Plan. 2007, 83, 62-69.

5. Vileniske, I.G. Influence of Built Heritage on Sustainable Development of Landscape. Landsc. Res. 2008, 33, 425-437.

6. Graham, B.; Howard, P. The Ashgate Research Companion to Heritage and Identity; Ashgate Publishing Company: Burlington, VT, USA, 2008.

7. Halbwachs, M.; Coser, L.A. On Collective Memory; University of Chicago Press: Chicago, IL, USA, 1992.

8. Ashworth, G.J.; Tunbridge, J.E.; Graham, B.J. Pluralising Pasts: Heritage, Identity and Place in Multicultural Societies; Pluto Press: London, UK, 2007.

9. UNESCO. Community Development through World Heritage. Available online: http://whc.unesco.org/documents/publi_wh_papers_31_en.pdf (accessed on 11 September 2015).

10. Lowenthal, D. Natural and cultural heritage. In The Nature of Cultural Heritage and the Culture of Natural Heritage: Northern Perspectives on a Contested Patrimony; Olwig, K.R., Lowenthal, D., Eds.; Routledge: New York, NY, USA, 2006.

11. Nijkamp, P.; Riganti, P. Assessing cultural heritage benefits for urban sustainable development. Int. J. Serv. Tech. Manag. 2008, 10, 29-37.

12. English Heritage Guidance Note to Circular for England on the Protection of World Heritage Sites, 2009. Available on: http://historicengland.org.uk/images-books/publications/protection-managementof-world-heritage-sites-in-england/ (accessed on 21 September 2015).

13. Lazrak, F.; Nijkamp, P.; Rietveld, P.; Rouwendal, J. Cultural Heritage and Creative Cities: An Economic Evaluation Perspective; (working paper) Series Research Memoranda 2009-30; VU University Faculty of Economics: Amsterdam, The Netherlands, 2009.

14. Bajec, J.F. Cultural Heritage as a Medium for the Establishment of Sustainable Development. Available online: http:/www.thetris.eu/wp-content/uploads/2014/05/Cultural-heritage-as-amedium.pdf.pdf?referer=silverstripe-dotnet-viewer/1.0.0 (accessed on 15 September 2015).

15. Heikkinen, H.I.; Lakomäki, S.; Baldridge, J. The dimensions of sustainability and the neo-entrepreneurial adaptation strategies in reindeer herding in Finland. J. Ecol. Anthropol. 2007, $11,24-41$.

16. WCCD. Our Creative Diversity; Report of the World Commission on Culture and Development; UNESCO Publishing: Paris, France, 1996.

17. Throsby, D. Cultural Sustainability. In A Handbook of Cultural Economics; Towse, R., Ed.; Edward Elgar Publishing Limited: Cheltenham, UK, 2003.

18. Huayhuaca, C.; Cottrell, S.; Raadik, J.; Gradl, S. Resident perceptions of sustainable tourism development: Frankenwald Nature Park, Germany. Int. J. Tour. Policy 2010, 3, 125-141.

19. Valentin, A.; Spangenberg, J.H. A guide to community sustainability indicators. Environ. Impact Assess. Rev. 2000, 20, 381-392. 
20. Spangenberg, J.H.; Valentin, A. Indicators for Sustainable Communities, 1999. Available online: http://www.academia.edu/339495/Indicators_for_Sustainable_Communities (accessed on 24 September 2015).

21. Eden, M.; Falkheden, L.; Malbert, B. The built environment and sustainable development: Research meets practice in a Scandinavian context. Plan. Theory Pract. 2000, 1, 260-272.

22. Spangenberg, J.H. Environmental space and the prism of sustainability: Frameworks for indicators measuring sustainable development. Ecol. Indic. 2002, 2, 295-309.

23. Gunn, C.A.; Var, T. Tourism Planning: Basics, Concepts and Cases, 4th ed.; Routledge: London, $\mathrm{UK}, 2002$.

24. Speck, E. The Fairmont Chateau Whistler Resort: Moving towards Sustainability. In Sustainable Tourism: A Global Perspective; Harris, R., Griffin, T., Williams, P., Eds.; Butterworth and Hienemann: Oxford, UK, 2002; pp. 269-283.

25. Waldron, D.; Williams, P.W. Steps towards sustainability monitoring: The case of the resort municipality of Whistler. In Sustainable Tourism: A Global Perspective; Harris, R., Griffin, T., Williams, P., Eds.; Butterworth and Hienemann: New York, NY, USA, 2002; pp. 180-194.

26. Johnson, H.; Wilson, G. Institutional sustainability: "Community" and waste management in Zimbabwe. Futures 2000, 32, 301-316.

27. Van der Duim, R.; Caalders, J. Biodiversity and tourism: Impacts and interventions. Ann. Tour. Res. 2002, 29, 743-761.

28. Mowforth, M.; Munt, I. Tourism and Sustainability: Development and New Tourism in the Third World, 2nd ed.; Routledge: London, UK, 2003.

29. Bramley, G.; Dempsey, N.; Power, S.; Brown, C. What is "social sustainability" and how do our existing urban forms perform in nurturing it? In Proceedings of the Sustainable Communities and Green Futures Conference, London, UK, 5-7 April 2006.

30. Shamai, S. Sense of Place: An Empirical Measurement. Geoforum 1991, 22, 347-358.

31. Tate, A. Making places different. In The Cultured Landscape: Designing the Environment in 21st Century; Harvey, S., Fieldhouse, K., Eds.; Routledge: London, UK, 2005; pp. 57-77.

32. Kaltenborn, B.P. Effects of Sense of Place on Responses to Environmental Impacts: A Study among Residents in Svalbard in the Norwegian High Arctic. Appl. Geogr. 1998, 18, 169-189.

33. Cottrell, J.R.; Cottrell, S.P. Sense-of-place influences on perceived environmental change effects on future holiday experiences to Saaremaa, Estonia. Scand. J. Hosp. Tour. 2015, doi:10.1080/ 15022250.2015.1024820.

34. Semken, S. Sense of Place and Place-Based Introductory Geoscience Teaching for American Indian and Alaska Native Undergraduate. J. Geosci. Educ. 2005, 53, 149-157.

35. Nash, V.; Christie, I. Making Sense of Community; Institute for Public Policy Research: London, UK, 2003.

36. Rogan. R.; O’Connor, M.; Horwitz, P. Nowhere to hide: Awareness and perceptions of environmental change, and their influence on relationships with place. J. Environ. Psychol. 2005, 25,147-158.

37. Talen, E. Sense of community and neighborhood form: An assessment of the social doctrine of new urbanism. Urban Stud. 1999, 36, 1361-1379.

38. Kearns, A.; Forrest, R. Social cohesion and multilevel governance. Urban Stud. 2000, 37, 995-1017. 
39. Bott, S.E. The development of psychometric scales to measure sense of place. 2000, unpublished work.

40. Williams, A.M.; Hall, C.M. Tourism, migration, circulation and mobility: The contingencies of time and place. In Tourism and Migration: New Relationships between Production and Reproduction; Hall, C.M., Williams, A.M., Eds.; Springer Netherlands: Dordrecht, The Netherlands, 2002; pp. 1-52.

41. Pretty, G.H.; Chipuerb, H.M.; Bramstona, P. Sense of place amongst adolescents and adults in two rural Australian towns: The discriminating features of place attachment, sense of community and place dependence in relation to place identity. J. Environ. Psychol. 2003, 23, 273-287.

42. Gross, M.J.; Brown, G. An empirical structural model of tourists and places: Progressing involvement and place attachment into tourism. Tour. Manag. 2008, 29, 1141-1151.

43. Lew, A. Introduction to special issue - Cultural geographies of tourism: Image, identity and place. Tour. Geogr. 2014, 16, 171-173.

44. Puhakka, R.; Cottrell, S.P.; Siikamäki, P.A. Sustainability Perspectives on Oulanka National Park, Finland: Mixed Methods in Tourism Research. J. Sustain. Tour. 2013, 22, 480-505.

45. Cottrell, S.P.; Raadik, J. Socio-cultural benefits of PAN Parks at Bieszscady National Park, Poland. Matkailututkimus 2008, 1, 56-67.

46. Cottrell, S.P.; Vaske, J.J.; Shen, F.; Ritter, P. Resident Perceptions of Sustainable Tourism in Chongdugou, China. Soc. Nat. Resour. 2007, 20, 511-525.

47. Bell, S. Nature for People: The Importance of Green Spaces to Communities in the East Midlands of England. In Wild Urban Woodlands; Kowarik, I., Körner, S., Eds.; Springer-Verlag: Berlin, Germany, 2005; pp. 81-94.

48. Dutcher, D.D.; Finley, J.C.; Luloff, A.E.; Johnson, J.B. Connectivity with Nature as a Measure of Environmental Values. Environ. Behav. 2007, 39, 474-493.

49. World Health Organization (WHO). Constitution of the World Health Organization; WHO: Geneva, Switzerland, 1948.

50. Greenberg, J.S. Health and Wellness: A Conceptual Difference. J. Sch. Health 1985, 55, 403-406.

51. Millennium Assessment. Ecosystems and Human Well-Being: A Framework for Assessment; Millennium Ecosystem Assessment Series; Island Press: Washington, DC, USA, 2003.

52. Burns, G.W. Naturally Happy, Naturally Healthy: The Role of the Natural Environment. In The Science of Well-being; Oxford University Press: Oxford, UK, 2006; pp. 405-431.

53. The European Landscape Convention. Available online: http://conventions.coe.int/Treaty/en/ Treaties/Html/176.htm (accessed on 21 September 2015).

54. Dempsey, N.; Bramley, G.; Power, S.; Brown, C. The Social Dimension of Sustainable Development: Defining Urban Social Sustainability. Wiley Int. Sci. 2009, doi:10.1002/SD.417.

55. Puhakka, R.; Sarkki, S.; Cottrell, S.P.; Siikamäki, P. Local discourses and international initiatives: Socio-cultural sustainability of tourism in Oulanka National Park, Finland. J. Sustain. Tour. 2009, 17, 529-549.

56. Shen, F.; Cottrell, S.P.; Morrison, K.; Hughey, K. Agritourism Sustainability in Mountain Rural Areas in China: A Community Perspective. Int. J. Bus. Glob. 2009, 3, 123-145.

57. Cottrell, S.P.; Vaske, J.J; Roemer, J.M. Resident Satisfaction with Sustainable Tourism: The case of Frankenwald Nature Park, Germany. Tour. Manag. Perspect. 2013, 8, 42-48. 
58. Ozdemir, A. Urban Sustainability and Open Space Networks. J. Appl. Sci. 2007, 7, 3713-3720.

59. Huseynov, F. Baku: Strategy of Sustainable Development. Urbanism 2005, 8, 41-53.

60. Beck, U. Risk Society: Towards a New Modernity; Sage Publications: London, UK, 1992.

61. Sachs, A. Eco-Justice: Linking Human Rights and the Environment; Worldwatch Paper 127; Worldwatch Institute: Washington, DC, USA, 1995.

62. Ferris, J.; Norman, C.; Sempik, J. People, land and sustainability: Community gardens and the social dimension of sustainable development. Soc. Adm. 2001, 35, 559-568.

63. Loures, L.; Santos, R.; Panagopoulos, T. Urban Parks and Sustainable City Planning-The Case of Partimao, Portugal. WSEAS Trans. Environ. Dev. 2007, 10, 171-180.

64. Grahn, P. Man's Needs for Urban Parks, Greenery and Recreation; Swedish Agricultural University: Lomma Municipality, Sweden, 1985.

65. Burgess J.; Harrison, C.; Limb, M. Parks and the urban green: a study of popular meaning and values for open spaces in the city. Urban Stud. 1988, 25, 455-473.

66. Conway, H. Parks and people: The social functions. In The Regeneration of Public Parks; Woudstra, J., Fieldhouse, K., Eds.; E\&FN Spon: London, UK, 2000.

67. Gehl, J.; Gemzoe, L. New City Spaces; Danish Architecture Press: Copenhagen, Danmark, 2001.

68. DeGraaf, D.A.; Jordan, D. Social Capital—How Parks and Recreation Help to Build Community. Parks Recreat. 2003, 38, 20-27.

69. Chiesura, A. The role of urban parks for the sustainable city. Landsc. Urban Plan. 2004, 68, 129-138.

70. Chang, C.Y.; Chen, P.K. Human Responses to Window Views and Indoor Plants in the Workplace. Hortic. Sci. 2005, 40, 1354-1359.

71. Rosenberger, R.S.; Bergerson, T.R.; Kline, J.D. Macro-Linkages between Health and Outdoor Recreation: The Role of Parks and Recreation Providers. J. Parks Recreat. Adm. 2009, 27, 8-20.

72. Peters, K. Being together in Urban Parks: Connecting Public Space. Leis. Sci. 2010, 32, 418-433.

73. IUCN. Caring for the Earth: A Strategy for Sustainable Living; The World Conservation Union, United Nation Environmental Program, Worldwide Fund for Nature: Gland, Switzerland, 1991.

74. Jongman, R.H.G. Nature conservation in Europe: Developing ecological networks. Landsc. Urban Plan. 1995, 32, 169-183.

75. Jongman, R.H.G.; Kulvik, M.; Kristiansen, A. European ecological networks and greenways. Landsc. Urban Plan. 2004, 68, 5-319.

76. Opdam, P.; Steingrover, E.; van Rooji, S. Ecological networks: A spatial concept for multi-actor planning of sustainable landscapes. Landsc. Urban Plan. 2006, 75, 322-332.

77. Zhang, L.; Wang, H. Planning and ecological network of Xiamen Island (China) using landscape metrics and network analysis. Landsc. Urban Plan. 2006, 78, 449-456.

78. Miller, R.W. Urban Forestry: Planning and Managing Urban Green Spaces; Prentice Hall: Englewood Cliffs, NJ, USA, 1988.

79. Grey, G.W. The Urban Forest: Comprehensive Management; Wiley: New York, NY, USA, 1996.

80. Teal, M.; Huang, C.S; Rodiek, J. Open space planning for Travis Country, Austin, Texas: A collaborative design. Landsc. Urban Plan. 1998, 42, 259-268.

81. Takano, T.; Nakamura, K.; Watanabe, M. Urban residential environments and senior citizens' longevity in megacity areas: The importance of walkable green spaces. J. Epidemiol. Community Health 2002, 56, 913-918. 
82. St. Leger, L. Health and Nature-New Challenges for Health Promotion. Health Promot. Int. 2003, 18, 173-175.

83. Maller, C.; Townsend, M.; Pryor, A.; Brown, P.; St. Leger, L. Healthy nature healthy people: 'Contact with nature' as an upstream health promotion intervention for populations. Health Promot. Int. 2005, 21, 45-54.

84. Ulrich, R.S. Natural versus urban sciences: Some psychological effects. Environ. Behav. 1981, 13, 523-556.

85. Rostami, R.; Hasanuddin, L.; Khoshnava, S.M.; Rostami, R. The Role of Historical Persian Gardens on the Health Status of Contemporary Urban Residents. Ecohealth 2014, 11, 308-321.

86. Kaplan, R. The analysis of perception via preference: A strategy for studying how the environment is experienced. Landsc. Plan. 1983, 12, 161-176.

87. Hartig, T.; Mang, M.; Evans, G. Restorative effects of natural environments experiences. Environ. Behav. 1991, 23, 3-26.

88. Godbey, G.; Graefe, A.; James, W. The Benefits of Local Recreation and Park Services: A Nationwide Study of Perceptions of the American Public; National Recreation and Parks Association: Arlington, VA, USA, 1992.

89. Eronene, S.; Nurmi, J.E.; Aro, K.S. Planning-Oriented, Avoidant, and Impulsive Social Reaction Styles: A Person-Oriented Approach. J. Res. Personal. 1997, 31, 34-57.

90. Thompson, C.W. Urban open space in the 21st century. Landsc. Urban Plan. 2002, 60, 59-72.

91. Tinsley, H.E.A.; Croskeys, C.E. Park Usage, Social Milieu, and Psychosocial Benefits of Parks Use Reported by Older Urban Park Users from Four Ethnic Groups. Leis. Sci. 2002, 24,199-218.

92. Coley, R.; Kuo, F.; Sullivan, W. Where does community grow? The social context created by nature in urban public housing. Environ. Behav. 1997, 29, 468-494.

93. Creswell, J.W. Educational Research: Planning, Conducting, and Evaluating Quantitative and Qualitative Approaches to Research; Merrill/Pearson Education: Upper Saddle River, NJ, USA, 2002.

94. Creswell, J.W. Research Design: Qualitative, Quantitative and Mixed Methods Approaches, 2nd ed.; Sage: Thousand Oaks, CA, USA, 2003.

95. Creswell, J.W.; Creswell, J.D. Mixed Methods Research: Developments, Debates and Dilemma. In Research in Organizations: Foundations and Methods of Inquiry; Berrett-Koehler Publishers: Oakland, CA, USA, 2009.

96. Decrop, A. Triangulation in qualitative tourism research. Tour. Manag. 1999, 20, 157-162.

97. Hunt, C.A.; Stronza, A. Bringing ecotourism into focus: Applying a hierarchical perspective to ecotourism research. J. Ecotour. 2009, 8, 1-17.

98. Wilber, D.N. Persian Garden's and Garden Pavilions; Dumbarton Oaks Research Library and Collection: Washington, DC, USA, 1979.

99. Hami, A.; Suhardi, B.M.; Manohar, M.; Shahhosseini, H. Users' Preferences of Usability and Sustainability of old Urban Park in Tabriz, Iran. Aust. J. Basic Appl. Sci. 2011, 5, 1899-2011.

100. Khosravaninezhad, S.; Abaszadeh, Z.; Karimzadeh, F.; Zadehbagheri, P. Parks and an Analysis of their Role in Improving the Quality of Urban Life, Using Seeking-Escaping Model. Case Study: Tehran Urban Parks. Available online: http://www.corp.at/archive/CORP2011_169.pdf (accessed on 10 September 2015). 
101. Mehta, V. Lively Streets: Exploring the Relationship between Built Environment and Social Behavior. Ph.D. Thesis, University of Maryland, College Park, MD, USA, 2006.

102. Shafer, E.J. Perception of Natural Environment. Environ. Behav. 1969, 1, 71-82.

103. Marshal, C.; Rossman, G.B. Designing Qualitative Research; Sage Publications: Los Angeles, CA, USA, 2010.

104. Bradley, C.; Millward, A. Successful Green Space-Do We Know It When We See It. Landsc. Res. 1986, 11, 2-8.

105. Gehl, J. Life between Buildings: Using Public Space; Arkitektens Forlag: Copenhagen, Denmark, 2001.

106. Dempsey, N. The Influence of the Quality of the Built Environment on Social Cohesion in English Neighbourhoods; Oxford Brookes University: Oxford, UK, 2006.

107. Cantrill, J.G.; Senecah, S.L. Using the "Sense of Place" Construct in the Context of Environmental Policy-Making and Landscape Planning. Environ. Sci. Policy 2001, 4, 185-203.

108. Ulrich, R.S. Aesthetic and affective response to natural environment. Behav. Nat. Environ. 1983, 6, 85-125.

109. Ulrich, R.S. View through a window may influence recovery from surgery. Science 1984, 224, 420-421.

110. Kaplan, S.; Kaplan, R. The Experience of Nature: A Psychological Perspective; Cambridge University Press: Cambridge, UK, 1989.

111. Kaplan, R. The Psychological Benefits of nearby Nature; Timber Press: Portland, OR, USA, 1992.

112. Kaplan, S. The Restorative Benefits of Nature: Toward an Integrative Framework. J. Environ. Psychol. 1995, 15, 169-182.

113. Grahn, P.; Stigsdotter, U.A. Landscape planning and stress. Urban For. Urban Green. 2003, 2, 1-18.

114. Nielsen, T.S.; Hansen, K.B. Do green areas affect health? Results from a Danish survey on the use of green areas and health indicators. Health Place 2007, 13, 839-850.

115. Kuo, F.E. Social Aspects of Urban Forestry: The Role of Arboriculture in a Healthy Social Ecology. Arboriculture 2003, 29, 148-155.

116. Kim, J.; Kaplan, R. Physical and Psychological Factors in Sense of Community: New Urbanism Kentland and Nearby Orchard Village. Environ. Behav. 2004, 36, 313-340.

117. Hidalgo, M.C.; Berto, R.; Galindo, M.P.; Getrevi, A. Identifying Attractive and Unattractive Urban Places: Categories, Restorativeness and Aesthetic Attributes. Medio Ambiente $y$ Comportamiento Humano 2006, 7, 115-133.

118. Lothian, A. Landscape and the Philosophy of Aesthetic: Is landscape Quality Inherent in the Landscape or in the Eye of Beholder. Landsc. Urban Plan. 1999, 44, 177-198.

119. Nasar, J.L. Adult Viewer's Preferences in Residential Scenes: A Study of the Relationship of Environmental Attributes to Preference. J. Environ. Behav. 1983, 32, 357-363.

120. Parsons, R.; Daniel, T. Good looking: In defense of scenic landscape aesthetics. Landsc. Urban Plan. 2002, 60, 43-56.

121. Purcell, T.; Peron, E.; Berto, R. Why do Preferences Differ between Scene Types? Environ. Behav. 2001, 33, 93-106. 
122. Ulrich, R.S. Health Benefits of Gardens in Hospitals. Available online: http://greenplantsforgreenbuildings.org/news/health-benefits-of-gardens-in-hospitals/ (accessed on 21 September 2015).

123. Karmanov, D.; Hamel, R. Assessing the restorative potential of contemporary urban environment(s): Beyond the nature versus urban dichotomy. Landsc. Urban Plan. 2008, 86, 115-125.

124. Rohde, C.L.E.; Kendle, A.D. Human Well-being, Natural Landscapes and Wildlife in Urban Areas: A Review. Available online: http://publications.naturalengland.org.uk/publication/2320898 (accessed on 24 September 2015).

125. Ashworth, G.J.; Graham, B. Senses of Place: Senses of Time; Ashgate: Surrey, UK, 2005.

(C) 2015 by the authors; licensee MDPI, Basel, Switzerland. This article is an open access article distributed under the terms and conditions of the Creative Commons Attribution license (http://creativecommons.org/licenses/by/4.0/). 